\title{
Transcranial direct current stimulation (tDCS) to Broca's area: persisting effects on non-verbal motor behaviors
}

\author{
K. E. Hupfeld ${ }^{1}$, C. J. Ketcham ${ }^{1 *}$ and H. D. Schneider ${ }^{2}$ \\ ${ }^{1}$ Department of Exercise Science, Elon University, USA \\ ${ }^{2}$ Brain Function Laboratory, Yale School of Medicine, USA
}

\begin{abstract}
Transcranial direct current stimulation (tDCS) has been investigated as a novel therapy for addressing motor, cognitive, and language deficits. While anodal tDCS to the primary motor cortex results in improved motor behaviors, few studies have examined if tDCS to other areas involved in motor output produces similar benefits. Although Broca's area is associated with speech production and grammar acquisition, it also contributes to motor planning and output in non-speech tasks. This study involved applying anodal tDCS to Broca's area and observing effects on non-verbal motor output. Twenty young adults completed two testing sessions separated by one week. Participants received either 30 minutes of $1.0 \mathrm{~mA}$ of anodal tDCS to Broca's area or sham stimulation. During stimulation (or sham), participants completed two tasks: (1) a limits of stability dynamic balance task and (2) a simple (SRT)/choice reaction time(CRT) tasks. Subjects who received tDCS to first performed significantly better on SRT and dynamic balance accuracy and showed a trend for dynamic balance speed when tested one week later compared to those who received sham stimulation first. These findings indicate that Broca's area is involved in the production of non-verbal motor behaviors and may have implications novel combined speech and movement therapy interventions.
\end{abstract}

\section{Introduction}

Both language and motor skills are imperative in all aspects of lifefor interacting with peers, holding a job, and completing activities of daily living. Impairments to language and motor capabilities negatively affect one's ability to lead an independent life. Thus, a dire need exists to develop effective therapies to address these deficits.

Both executing complex motor skills and using grammatically complex sentences require the hierarchical organization of sequences and temporal processing [1,2]. Generally, speech involves piecing individual words together in a precise order based on the rules of grammar (i.e., syntax) to form sentences [3]. Speech also requires temporal organization of smaller components-as placing the morpheme " $\mathrm{s}$ " in a different position in a sentence changes the sentence meaning (e.g., "the girls jump" vs. "the girl jumps") [2].

Similarly, performing movements requires the ability to string together smaller actions in the correct order based on learned rules $[3,4]$. When completing both simple and complex tasks-from picking up a block to walking across a balance beam-one must progress through smaller movements in the appropriate sequence and at the right times (e.g., opening the fingers, reaching for the block with an appropriate speed, curling the fingers around the block, etc.) $[2,4]$. Thus, similar neural pathways are likely involved in the planning components of both language and movement.

Planning processes for motor actions and language are known to heavily rely on frontal-basal ganglia (BG) circuits (i.e., corticostriatal pathways), as well as frontal-cerebellar pathways (which subserve a broad variety of non-motor language processes) [5]. In the frontal cortex, the pre-supplementary motor area (pre-SMA), supplementary motor area (SMA), and Broca's area all play a significant role in planning processes (and in procedural learning) [6] and possess functional connections with the BG [7].

Broca's area has recently been associated with corticostriatal pathways, including a pathway that originates in posterior Broca's area, converges on the anterior putamen of the BG, and seems to subserve the procedural memory system and represent the neural substrate for grammatical function [8]. Moreover, posterior Broca's area possesses functional connections with the SMA, a region highly implicated in planning and sequencing motor behaviors $[9,10]$. Thus, the involvement of Broca's area in these pathways indicates its potential role in planning/sequencing for both speech and nonspeech behaviors. These roles make Broca's area a promising target for potential therapeutic interventions.

Identified just over 150 years ago, by Paul Broca as a center of speech production, Broca's area is known to play a substantial role in the planning of speech [9], in the serial processing of language [1,3], and in one's ability to listen to and comprehend language [11]. Broca's area is activated when performing artificial grammar tasks (i.e., learning non-sense grammar rules), suggesting its role in extracting rules from sequences [12]. Lesions to Broca's area often result in Broca's aphasia, which typically includes agrammatism, or difficulty understanding and/or using correct syntax while speaking $[13,14]$.

Correspondence to: Caroline J. Ketcham, PhD 2525 Campus Box, Elon, NC 27244, USA Tel: (336) 278-5807, E-mail: cketcham@elon.edu

Running Title: Motor performance with tDCS to Broca's area

Key words: transcranial direct current stimulation (tDCS), Broca's area, motor planning

Received: December 17, 2016; Accepted: January 19, 2017; Published: January 24,2017 
Recent functional imaging studies have identified other roles of Broca's area not specifically related to speech/language production [1]. Broca's area has been implicated in sight-reading and performing music [15], as well as during visual search [16] and visual spatial cognition [15]. Additionally, Broca's area and its right homolog have been associated with the "mirror neuron system," which allows individuals to recognize and imitate the actions of others [17]. Broca's area also appears to play a role in movement, including motor ideation, planning [18], and action execution [19].

As both language and action require significant planning, Broca's area (particularly the posterior portion) has been suggested as a shared syntactic processor for organizing hierarchical, sequential actions in both domains (and possibly as a processor for any type of hierarchical sequence) $[3,20,21]$. Inhibiting posterior Broca's area using transcranial magnetic stimulation (TMS) impairs performance on a serial reaction time task [22] and on a finger-tapping sequence learning task [3], indicating the role of posterior Broca's in organizing and storing information while learning new sequences, including for patterns that are unrelated to speech. TMS is a type of stimulation that directs magnetic stimulation to brain and essentially stops function of that area momentarily [3,22].

Posterior Broca's area also appears to be involved in "chunking"the process of grouping consecutive items in a sequence to decrease memory load (e.g., remembering phone numbers as groups of 3-3-4 numbers instead of as a group of 10) [4]. Disrupting posterior Broca's area with TMS slows processing time of higher-order chunks during a perceptual sequence learning task and decreases the efficiency of chunking strategies [4]. As chunking is an important mechanism for processing information in multiple domains, such as learning new motor, cognitive, and perceptual information, Broca's area appears to be a central processing structure for planning and sequence learning in many more behaviors than just language [4].

\section{Assessing planning capabilities}

Reaction time (RT) represents one method to assess the planning capabilities of Broca's area in motor a task unrelated to speech/ language production. RT involves three main components: stimulus identification, response selection, and movement execution. Faster RTs indicate more efficient planning for a movement (e.g., the more prepared the motor system is to move, the faster a person will be able to react to a stimulus and reach for a target) $[23,24]$ While simple reaction time (SRT) tasks only manipulate stimulus identification (e.g., by varying the time between each subsequent stimulus), choice reaction time (CRT) tasks involve more unpredictability, which slows the response selection process and results in slower RTs (e.g., if one is unsure about which of eight targets they will need to reach for, they will not be able to fully plan the movement until they identify the stimulus, causing them to react more slowly). For this study, we tested SRT and CRT, which both likely involve planning calculations via Broca's area.

As another measure of non-verbal planning, this study included a dynamic balance aiming task that required participants to correctly shift their center of mass (COM) to reach the indicated target on a screen in front of them. Similar to one's finger during the SRT and CRT tasks, participants' COM functioned as an aiming tool during the balance task. However, this task represented a more complex version of SRT and CRT. After seeing the indication to proceed (i.e., stimulus identification), participants had to determine which of eight targets was correct and plan how to manipulate their body to reach the target (i.e., response selection). Participants then had to effectively coordinate their visual, vestibular, and somatosensory systems, as well as coordinate their muscles to shift their COM, to complete the desired movement (i.e., movement execution). Thus, compared to SRT and CRT, the balance task required more complex planning.

\section{tDCS}

To investigate the role of Broca's area in planning for non-verbal motor actions, we utilized a noninvasive brain stimulation technique called transcranial direct current stimulation (tDCS). tDCS passes a weak electrical current between two electrode sponges, the anode and cathode, placed on the subject's scalp [25]. Research has shown that anodal tDCS transiently facilitates (i.e., depolarizes) and cathodal stimulation defacilitates (i.e., hyperpolarizes) neuronal resting membrane potential without actually inducing action potentials $[25,26]$ Anodal tDCS may be applied to a specific cortical area to improve the functional connectivity of a given pathway and elicit behavioral changes, such as improvements in motor [27,28], cognitive [29], and speech [30] capabilities. tDCS is capable of influencing both cortical and subcortical areas [31].

A few studies have investigated the effects of tDCS to Broca's area on various aspects of language. Anodal tDCS to Broca's area during the acquisition phase of an artificial grammar task enhances learning/ performance [32]. Anodal tDCS to Broca's area has also been shown to enhance verbal fluency [33] and improve performance on a picturenaming task in healthy adults [34]. In a longer-term study, after training on a repetition task for five days, aphasic patients showed greater accuracy in the tDCS vs. sham condition [35]. These improvements transferred to other language abilities, including word repetition, reading, and written naming, and improvements lasted for two months after $\mathrm{tDCS}$ - suggesting the ability of tDCS to induce lasting benefits in clinical populations [35]. However, no studies to date have investigated the effects of tDCS to Broca's area on behaviors unrelated to language.

\section{Study rationale}

The idea for this study developed from collaborating with a clinician who treats minimally verbal children with ASD. He works with his patients for a long duration, applying tDCS to children for three consecutive days during a speech therapy intervention about five times per year. While observing patients' behaviors over time, we anecdotally noticed that, as speech areas were stimulated with tDCS, children exhibited improvements not only in correct grammar use, but also in their motor abilities. For instance, while receiving tDCS to Broca's area, one child successfully walked across a balance beam-a task that he was never able to do before starting tDCS therapy [36]. These observations sparked questions about the relationships between the language and motor systems, including whether overlapping neural pathways might allow for the stimulation of one system with tDCS, but result in the facilitation of both language and motor behaviors.

Although a few studies have found that anodal tDCS to the SMA (a motor area) improves motor planning behaviors [37-40], no previous studies have tested whether tDCS might facilitate the planning abilities of Broca's area (a speech/language area) during non-verbal motor tasks. In particular, this study will investigate whether anodal tDCS to Broca's area influences performance on a SRT, CRT, and dynamic balance aiming task. As our previous work has indicated that anodal tDCS to the SMA results in faster/more accurate performance on these motor tasks, we hypothesize that stimulating Broca's area will elicit similar motor behavioral improvements. 


\section{Methods}

\section{Participants}

Twenty right-handed young adults, ages 18 to $22(4 \mathrm{M}, 16 \mathrm{~F})$, volunteered as subjects. No subjects disclosed neurologic, sensory, or motor impairments. All participants provided written informed consent, and this study was approved by the Institutional Review Board and performed in accordance with the Declaration of Helsinki.

\section{tDCS}

Stimulation was delivered to participants using a Dupel iontophoresis device (Empi Inc.). Two electrode sponges (each 25 $\mathrm{cm}^{2}$, Amrex) saturated with sterile saline $(0.9 \% \mathrm{NaCl})$ were placed on the scalp. The anode was placed over FC5, which corresponds to Broca's area based on the International 10-20 Extended system for EEG electrode placement $[34,41]$. The cathode was used as a reference lead and placed over the right supraorbital area. During each tDCS session, participants received $1.0 \mathrm{~mA}$ of current for 30 minutes at an average charge density of $0.072 \mathrm{C} / \mathrm{cm}^{2}$, which is well within established safe limits [42].

Only a transient minimal superficial external integumentary physical risk to participants existed, and participants were fully informed of these risks before beginning the study. Systematic investigations of the behavioral effects of tDCS have been conducted for at least the past 40 years [43]. Protocols for administering tDCS have been comprehensively investigated, and side effects from stimulation are limited to a mild tingling sensation, itching, and fatigue [44,28].

\section{Experimental design}

Participants were counterbalanced to complete either the tDCS condition (30 minutes of anodal tDCS to Broca's area) or the sham condition (five seconds of tingling before the device was turned off). They then came back for the opposite condition one week later. Participants waited 10 minutes after tDCS was started to begin the tasks [45]. Conditions were separated by one week to account for possible learning effects. During stimulation (or sham), participants completed two motor tasks both times: (1) SRT and CRT tasks and (2) a limits of stability dynamic balance task which were presented in random order.

\section{Reaction time tasks}

RT measures included an SRT and a CRT task using a MOART Reaction Time and Movement Time Panel (Lafayette Instruments) (Figure 1). Both RT and movement time (MT) were recorded for each

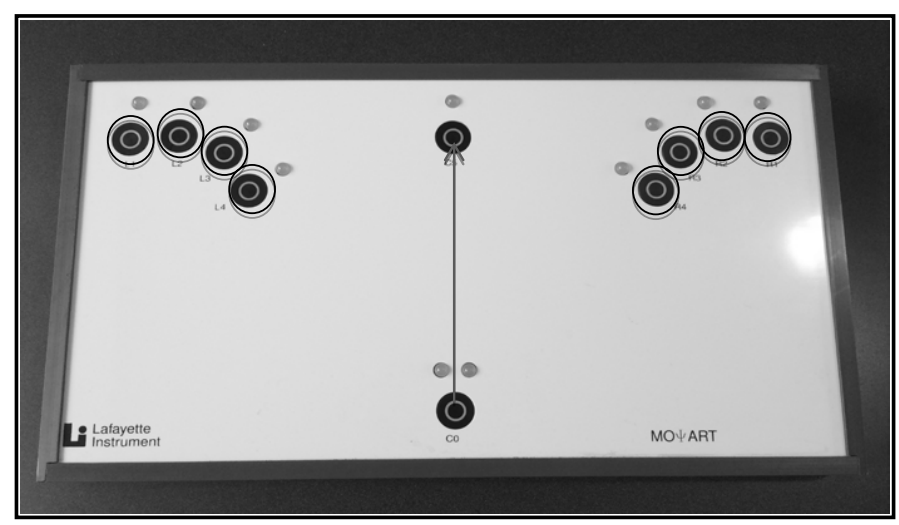

Figure 1. MOART Reaction Time and Movement Time Panel (Lafayette Instruments). Gray arrow indicates pathway/target for SRT. Black circles indicate the eight possible targets for CRT. task. During the SRT task, after hearing an auditory stimulus and seeing the stimulus light turn red, participants were instructed to remove their finger from the home key (SRT) and touch a target directly in front of them $\left(\mathrm{MT}_{\mathrm{SRT}}\right)$ as quickly as possible.

During the CRT task, participants also heard an auditory stimulus and saw the stimulus light turn red, after which they removed their finger from the home key (CRT) and subsequently touched whichever of eight targets lit up red as quickly as possible $\left(\mathrm{MT}_{\mathrm{CRT}}\right)$. One target was situated on the ipsilateral side to the individual's dominant hand, and the other target was on situated on the contralateral side. Both tasks included delays of between one and four seconds between each subsequent stimulus to make the stimulus timing unpredictable. Participants performed five practice trials in order to familiarize them with the task [46], followed by 25 recorded trials for both SRT and CRT.

\section{Balance tasks}

Participants completed a Limits of Stability dynamic balance task using a Biodex Balance System (Biodex). Participants stood on a stationary/firm surface and were required to shift their COM to reach and pause at different targets for 0.25 seconds displayed on the screen in front of them (Figure 2). Participants completed a thirty second familiarization period on the Biodex, practicing shifting their COM to reach the different targets. Participants then completed two recorded trials during each testing period. While the SRT and CRT tasks were able to differentiate RT from MT, this task did not distinguish between the participant's RT to each new stimulus and the MT taken to reach to the next target. Instead, multiple targets were linked together and RT and MT were both embedded within the task. Faster total MT to each new target corresponded with faster initial RT to the stimulus (and thus more proficient planning for the next action).

\section{Data analysis}

Data was analyzed using SPSS (Version 22). A repeated-measures MANOVA for Time was conducted for SRT; CRT; $\mathrm{MT}_{\mathrm{SRT}} ; \mathrm{MT}_{\mathrm{CRT}}$; dynamic balance speed and accuracy for the both groups (sham first; tDCS first). The alpha level was set at $\mathrm{p}<0.05$, and trends were reported for $\mathrm{p}<0.10$.

\section{Results}

All participants tolerated tDCS treatment without any adverse effects. There was a trend toward a significant multivariate time effect for

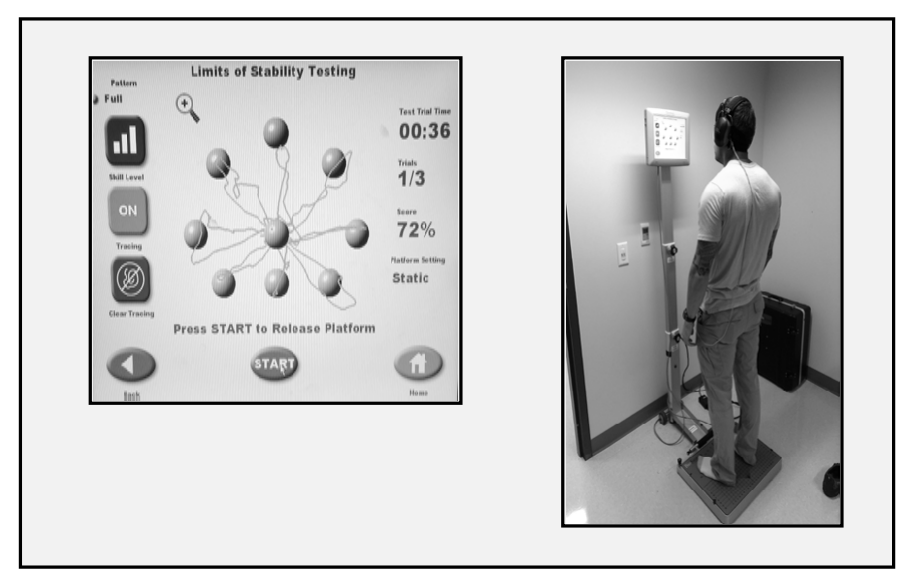

Figure 2. (Above) Display showing a subject's COM trace during the Biodex Balance System Limits of Stability task; (Right) Participant completing the task while receiving tDCS to Broca's area 
the tDCS first group $\left(\mathrm{F}_{(6,4)}=4.57, \mathrm{p}=0.081\right)$. There was not a significant multivariate time effect or trend for the sham first group $(\mathrm{p}=0.50)$. We did look at univariate comparisons to present below. There was a trend towards a significant Time effect for SRT in the group that received tDCS first $\left(\mathrm{F}_{(1,9)}=4.03, \mathrm{p}=0.07\right)$, but not in the group that received sham stimulation first $(\mathrm{p}=0.44)$ (Figure 3$)$. For $\mathrm{SRT}_{\mathrm{MT}}$, no significant Time effects occurred in either group $(\mathrm{p}>0.10)$.

There were not significant Time effects for either group for CRT $(\mathrm{p}>0.10)$. For $\mathrm{CRT}_{\mathrm{MT}}$, there was a significant Time effect for the group that received tDCS first $\left(\mathrm{F}_{(1,9)}=5.56, \mathrm{p}<0.04\right)$, but the group that received sham stimulation first did not $(\mathrm{p}=0.27)$. However, this effect was in the opposite direction as expected because both groups showed slower $\mathrm{CRT}_{\mathrm{MT}}$ over time.

As depicted in Figure 4, there were changes in balance across time. There was a trend for the group that received tDCS first $\left(\mathrm{F}_{(1,9)}=4.25\right.$, $\mathrm{p}=0.07)$, but not for the group that received sham stimulation first $(\mathrm{p}=0.16)$. For balance accuracy both groups showed a significant time effect ( $\mathrm{tDCS}, \mathrm{F}_{(1,9)}=11.31, \mathrm{p}=0.008$; sham, $\mathrm{F}_{(1,9)}=8.69$, $\mathrm{p}=0.016$; Figure $5)$. We did assess mean balance accuracy for each group. Balance accuracy increased by $25.5 \%$ between the two sessions for the group that received tDCS first, compared to an increase of $19 \%$ in mean accuracy of the sham group.

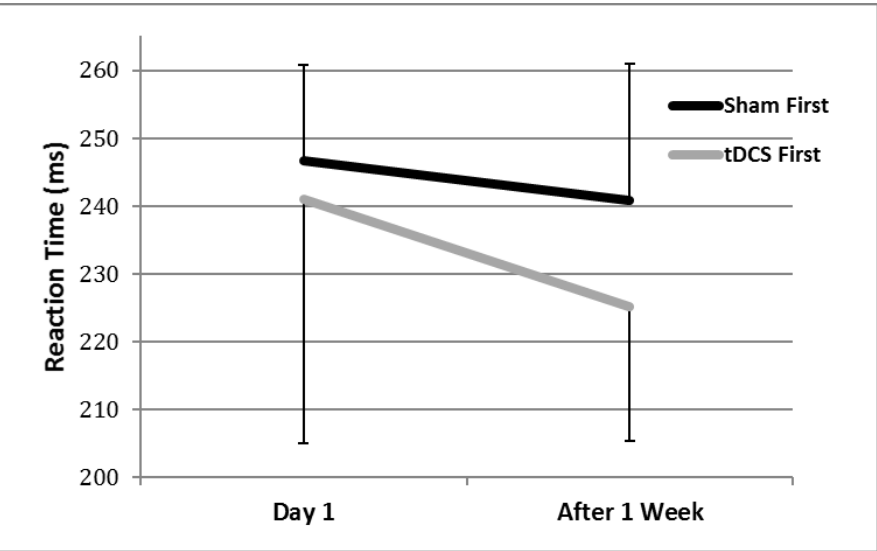

Figure 3. Simple reaction time (SRT) over the two testing sessions. Post-hoc analysis indicated a trend towards significant improvement in SRT between Time 1 and Time 2 in the group that received tDCS first (indicated by the gray line), but not in the group that received sham stimulation first (indicated by the black line).

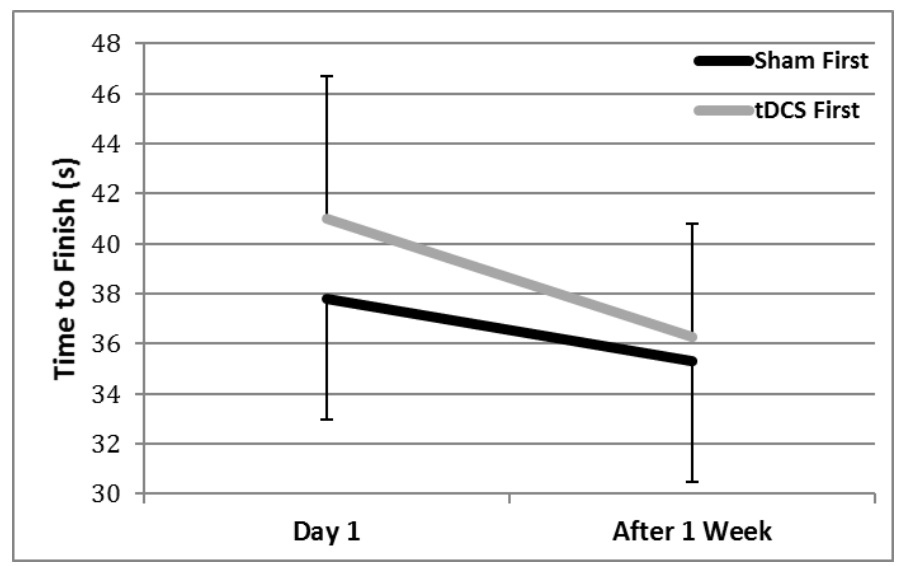

Figure 4. Time to complete the dynamic balance task. Post-hoc analysis showed a trend towards a significant Time effect for the group that received tDCS first (indicated by the gray line), but no significant Time effect for the group that received sham stimulation first (indicated by the black line)

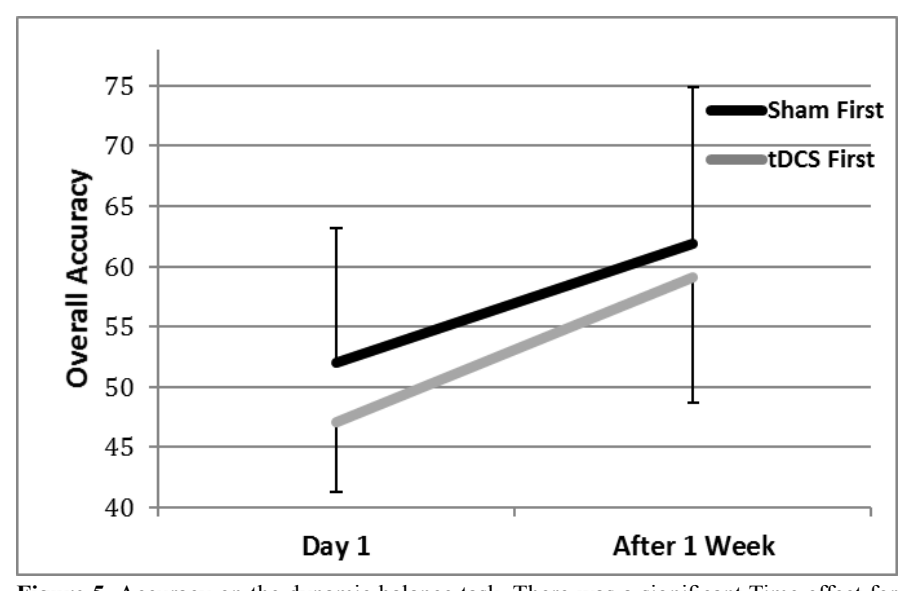

Figure 5. Accuracy on the dynamic balance task. There was a significant Time effect for both groups, indicating learning between Time 1 and Time 2, although a greater percent increase in mean accuracy was found for the group that received tDCS first

\section{Discussion}

This study examined whether anodal tDCS to Broca's area influences performance on RT and balance. These tasks varied in complexity and each required some degree of planning to execute. One week later, the group that received tDCS first showed significant improvement in SRT and a trend towards improvement in time to complete the balance task, while the group that received sham first did not. Moreover, the group that received $\mathrm{tDCS}$ first showed a greater percent improvement in mean balance accuracy after one week compared to the group that received sham first. All of these findings suggest that tDCS to Broca's area may have helped facilitate motor planning processes and training of the motor system to result in greater improvements to motor behaviors after a one week delay compared to the sham condition.

In contrast to traditional views that consider Broca's area only as a speech production center, more recent work has implicated Broca's area in non-speech functions, including planning/executing motor behaviors $[18,19]$ and in organizing hierarchical, sequential actions in any domain $[3,20,21]$. Consequently, Broca's area is likely involved in the planning processes necessary to complete RT and balance aiming tasks. As neither of these tasks is heavily based on learned motor sequences, these findings support a general role of Broca's area in motor planning, including for non-sequential, non-verbal motor behaviors.

Performance on each of these tasks likely improved because tDCS to Broca's area may have facilitated a greater state of preparation to perform each task through depolarizing neurons associated with Broca's area and thus speeding up planning calculations [25]. Moreover, tDCS may have helped to "prime" cortical excitability (i.e., improve functional connectivity and efficiency) in the functional pathways associated with Broca's area, including corticostriatal pathways $[8,35,31]$ and connections between Broca's area and the SMA [10].

Improvements were evident in tasks of varying complexity, from SRT to a complex balance aiming task. This indicates that the Broca's area is involved in the planning processes for a wide range of movements (more than just organizing highly sequential motor behaviors) and that tDCS may be able to enhance planning via Broca's area for a variety of behaviors. This supports the hypothesis that the motor and grammatical speech systems are highly overlapping, and that facilitating the procedural language system with anodal tDCS is able to also enhance planning processes in the motor system [36]. These 
findings are supportive of our anecdotal observations of concomitantly improving motor and speech behaviors during tDCS interventions targeting speech cortical areas.

An interesting finding in this study included how effects were delayed-motor improvements were seen one week later in the group that received tDCS first. If the first session is viewed as "training," those who received tDCS first were able to train on the tasks for thirty minutes while receiving stimulation to Broca's area before being tested a second time one week later. Contrarily, those who received sham stimulation first did not receive the benefits of tDCS-augmented training until the second session. Due to modulation of neuronal resting membrane potential and effects on subcortical pathways, training with tDCS may have helped subjects learn to more efficiently plan the sequence of movements needed to complete the RT tasks and learn how to best plan to manipulate their COM to reach the targets, resulting in faster/ more accurate performance on both tasks the following week.

\section{Therapeutic applications of tDCS}

Many individuals with Autism Spectrum Disorder (ASD) exhibit profound decrements in planning for both motor and language [47$49,6]$. Moreover, a significant body of literature has noted abnormal connectivity in multiple pathways in those with ASD, particularly in the brain regions associated with the corticostriatal circuits that subserve planning [50,51].

As tDCS is hypothesized to improve functional connectivity, tDCS represents a promising rehabilitation tool for this population. Low cost, portable, and user-friendly, tDCS could be easily implemented into clinics to augment therapies. As only one training session resulted in persisting motor improvements in neurologically unimpaired individuals one week later, combining tDCS with motor/language training might elicit even greater benefits in those with ASD [52-58].

\section{Conclusion}

This study represents the first to apply tDCS to Broca's area and investigate effects on non-verbal behaviors. Improvements were evident in SRT and balance (accuracy and time) one week after thirty minutes of training on these tasks while receiving tDCS to Broca's area. tDCS likely facilitated functional connections between Broca's area and the SMA and corticostriatal connections (including those subserving the procedural memory system) to enhance motor planning. These findings indicate both that Broca's area is involved in planning nonverbal motor behaviors, in a more generalized manner than just facilitating highly sequential motor actions, and that tDCS is capable of targeting Broca's area. This persisting response to tDCS has obvious implications for designing combined speech/motor therapies for those with planning deficits such as individuals with ASD.

\section{References}

1. Burns MS, Fahy J (2010) Broca's area: rethinking classical concepts from a neuroscience perspective. Top Stroke Rehabil 17: 401-410. [Crossref]

2. Damasio A, Meyer K (2008) Behind the looking-glass. Nature 454: 167-168. [Crossref]

3. Clerget E, Badets A, Duqué J, Olivier E (2011) Role of Broca's area in motor sequence programming: a cTBS study. Neuroreport 22: 965-969. [Crossref]

4. Alamia A, Solopchuk O, D'Ausilio A, Van Bever V, Fadigo L, et al. (2016) Disruption of Broca's area alters higher-order chunking processing during perceptual sequence learning. J Cogn Neurosci 28: 402-417. [Crossref]

5. Mariën P, Ackermann H, Adamaszek M, Barwood CH, Beaton A, et al. (2014) Consensus paper: Language and the cerebellum: an ongoing enigma. Cerebellum 13: 386-410. [Crossref]
6. Walenski M, Tager-Flusberg H, Ullman MT (2006) Language in autism. In S. O. Moldin \& J. L. R. Rubenstein (Eds.), Understanding Autism: From basic neuroscience to treatment (pp. 175-203). Boca Raton, FL: CRC Press.

7. Ullman MT (2013) The role of declarative and procedural memory in disorders of language. Linguistic Variation 13: 133-154.

8. Ford AA, Triplett W, Sudhyadhom A, Gullett J, McGregor K, et al. (2013) Broca's area and its striatal and thalamic connections: a diffusion-MRI tractography study. Front Neuroanat 7: 8. [Crossref]

9. Andrewes D (2016) Neuropsychology: From theory to practice. New York, NY: Routledge.

10. Ford A, McGregor KM, Case K, Crosson B, White KD (2010) Structural connectivity of Broca's area and medial frontal cortex. Neuroimage 52: 1230-1237. [Crossref]

11. Novick JM, Trueswell JC, Thompson-Schill SL (2005) Cognitive control and parsing: reexamining the role of Broca's area in sentence comprehension. Cogn Affect Behav Neurosci 5: 263-281. [Crossref]

12. Forkstam C, Hagoort P, Fernandez G, Ingvar M, Petersson KM (2006) Neural correlates of artificial syntactic structure classification. Neuroimage 32: 956-967. [Crossref]

13. Christiansen MH, Louise Kelly M, Shillcock RC, Greenfield K (2010) Impaired artificial grammar learning in agrammatism. Cognition 116: 382-393. [Crossref]

14. Ullman MT (2006) Is Broca's area part of a basal ganglia thalamocortical circuit? Cortex 42: 480-485. [Crossref]

15. Sluming V, Brooks J, Howard M, Downes JJ, Roberts N (2007) Broca's area supports enhanced visuospatial cognition in orchestral musicians. J Neurosci 27: 3799-3806. [Crossref]

16. Fink GR, Manjaly ZM, Stephan KE, Gurd JM, Zilles K, et al. (2006). A role for Broca's area beyond language processing: Evidence from neuropsychology and fMRI. In Y. Grodzinsky \& K. Amunts (Eds.), Broca's region (pp. 254-268). New York, NY: Oxford University Press.

17. Iacoboni M, Dapretto M (2006) The mirror neuron system and the consequences of its dysfunction. Nat Rev Neurosci 7: 942-951. [Crossref]

18. Thoenissen D, Zilles K, Toni I (2002) Differential involvement of parietal and precentral regions in movement preparation and motor intention. J Neurosci 22: 90249034. [Crossref]

19. Parsons LM, Fox PT, Downs JH, Glass T, Hirsch TB, et al. (1995) Use of implici motor imagery for visual shape discrimination as revealed by PET. Nature 375: 54-58. [Crossref]

20. Fadiga L, Craighero L, D'Ausilio A (2009) Broca's area in language, action, and music. Ann N Y Acad Sci 1169: 448-458. [Crossref]

21. Koechlin E, Jubault T (2006) Broca's area and the hierarchical organization of human behavior. Neuron 50: 963-974. [Crossref]

22. Clerget E, Poncin W, Fadiga L, Olivier E (2012) Role of Broca's area in implicit motor skill learning: evidence from continuous theta-burst magnetic stimulation. $J \operatorname{Cog} n$ Neurosci 24: 80-92. [Crossref]

23. Niemi P, Näätänen R (1981) Forperiod and simple reaction time. Psychological Bulletin, 89: 133-162.

24. Rinehart NJ, Bradshaw JL, Brereton AV, Tonge BJ (2001) Movement preparation in high-functioning autism and Asperger disorder: a serial choice reaction time task involving motor reprogramming. J Autism Dev Disord 31: 79-88. [Crossref]

25. Filmer HL, Dux PE, Mattingley JB (2014) Applications of transcranial direct curren stimulation for understanding brain function. Trends Neurosci 37: 742-753.[Crossref]

26. Nitsche MA, Fricke K, Henschke U, Schlitterlau A, Liebetanz D, et al. (2003) Pharmacological modulation of cortical excitability shifts induced by transcranial direct current stimulation in humans. J Physiol 553: 293-301. [Crossref]

27. Boggio PS, Ferrucci R, Rigonatti SP, Covre P, Nitsche M, et al. (2006) Effects of transcranial direct current stimulation on working memory in patients with Parkinson's disease. J Neurol Sci 249: 31-38. [Crossref]

28. Madhavan S, Shah B (2012) Enhancing motor skill learning with transcranial direct current stimulation - a concise review with applications to stroke. Front Psychiatry 3: 66. [Crossref]

29. Miniussi C, Cappa SF, Cohen LG, Floel A, Fregni F, et al. (2008) Efficacy of repetitive transcranial magnetic stimulation/transcranial direct current stimulation in cognitive neurorehabilitation. Brain Stimul 1: 326-336. [Crossref] 
30. Schneider HD, Hopp JP (2011) The use of the Bilingual Aphasia Test for assessment and transcranial direct current stimulation to modulate language acquisition in minimally verbal children with autism. Clin Linguist Phon 25: 640-654. [Crossref]

31. Polanía R, Paulus W, Nitsche MA (2012) Modulating cortico-striatal and thalamocortical functional connectivity with transcranial direct current stimulation. Hum Brain Mapp 33: 2499-2508. [Crossref]

32. de Vries MH, Barth AC, Maiworm S, Knecht S, Zwitserlood P, et al. (2010) Electrical stimulation of Broca's area enhances implicit learning of an artificial grammar. $J \operatorname{Cog} n$ Neurosci 22: 2427-2436. [Crossref]

33. Cattaneo Z, Pisoni A, Papagno C (2011) Transcranial direct current stimulation over Broca's region improves phonemic and semantic fluency in healthy individuals. Neuroscience 183: 64-70. [Crossref]

34. Holland R, Leff AP, Josephs O, Galea JM, Desikan M, et al. (2011) Speech facilitation by left inferior frontal cortex stimulation. Curr Biol 21: 1403-1407. [Crossref]

35. Marangolo P, Marinelli CV, Bonifazi S, Fiori V, Ceravolo MG, et al. (2011) Electrical stimulation over the left inferior frontal gyrus (IFG) determines long-term effects in the recovery of speech apraxia in three chronic aphasics. Behav Brain Res 225: 498-504. [Crossref]

36. Schneider HD, Livitz IE, Schneider D (2013) Sustainable learning for sustainability. Journal of Organizational Transformation \& Social Change 10: 124-147.

37. Carlsen AN, Eagles JS, MacKinnon CD (2015) Transcranial direct current stimulation over the supplementary motor area modulates the preparatory activation level in the human motor system. Behav Brain Res 279: 68-75. [Crossref]

38. Carter MJ, Maslovat D, Carlsen AN (2015) Anodal transcranial direct current stimulation applied over the supplementary motor area delays spontaneous antiphaseto-in-phase transitions. J Neurophysiol 113: 780-785. [Crossref]

39. Hayduk-Costa G, Drummond NM, Carlsen AN (2013) Anodal tDCS over SMA decreases the probability of withholding an anticipated action. Behav Brain Res 257: 208-214. [Crossref]

40. Vollmann H, Conde V, Sewerin S, Taubert M, Sehm B, et al. (2013) Anodal transcranial direct current stimulation (tDCS) over supplementary motor area (SMA) but not preSMA promotes short-term visuomotor learning. Brain Stimul 6: 101-107. [Crossref]

41. Oostenveld R, Praamstra P (2001) The five percent electrode system for high-resolution EEG and ERP measurements. Clin Neurophysiol 112: 713-719. [Crossref]

42. Liebetanz D, Koch R, Mayenfels S, König F, Paulus W, et al. (2009) Safety limits of cathodal transcranial direct current stimulation in rats. Clin Neurophysiol 120: 11611167. [Crossref]

43. Priori A (2003) Brain polarization in humans: a reappraisal of an old tool for prolonged non-invasive modulation of brain excitability. Clin Neurophysiol 114: 589-595. [Crossref]
44. Poreisz C, Boros K, Antal A, Paulus W (2007) Safety aspects of transcranial direct current stimulation concerning healthy subjects and patients. Brain Res Bull 72: 208 214. [Crossref]

45. Nitsche MA, Paulus W (2000) Excitability changes induced in the human motor cortex by weak transcranial direct current stimulation. J Physiol 527 Pt 3: 633-639. [Crossref]

46. Pascual-Leone A1, Brasil-Neto JP, Valls-Solé J, Cohen LG, Hallett M (1992) Simple reaction time to focal transcranial magnetic stimulation. Comparison with reaction time to acoustic, visual and somatosensory stimuli. Brain 115 Pt 1: 109-122. [Crossref]

47. Fournier KA, Hass CJ, Naik SK, Lodha N, Cauraugh JH (2010) Motor coordination in autism spectrum disorders: a synthesis and meta-analysis. J Autism Dev Disord 40: 1227-1240. [Crossref]

48. Rinehart NJ, Bellgrove MA, Tonge BJ, Brereton AV, Howells-Rankin D, et al. (2006) An examination of movement kinematics in young people with high-functioning autism and Asperger's disorder: further evidence for a motor planning deficit. $J$ Autism Dev Disord 36: 757-767. [Crossref]

49. Ullman MT (2004) Contributions of memory circuits to language: the declarative/ procedural model. Cognition 92: 231-270. [Crossref]

50. Kenet T, Orekhova EV, Bharadwaj H, Shetty NR, Israeli E, et al. (2012) Disconnectivity of the cortical ocular motor control network in autism spectrum disorders. Neuroimage 61: 1226-1234. [Crossref]

51. Mostofsky SH, Powell SK, Simmonds DJ, Goldberg MC, Caffo B, et al. (2009) Decreased connectivity and cerebellar activity in autism during motor task performance. Brain 132: 2413-2425. [Crossref]

52. Friederici AD (2002) Towards a neural basis of auditory sentence processing. Trends Cogn Sci 6: 78-84. [Crossref]

53. Gelfand JR, Bookheimer SY (2003) Dissociating neural mechanisms of temporal sequencing and processing phonemes. Neuron 38: 831-842. [Crossref]

54. Cognitive, Affective, \& Behavioral Neuroscience 5: 263-281.

55. Rinehart N, Tonge B, Brereton A, Bradshaw J (2010) Attentional blink in young people with high-functioning autism and Asperger's disorder. Autism 14: 47-66. [Crossref]

56. Lenzi MM, Alexandria AK, Ferreira DM, Maia LC (2015) Does trauma in the primary dentition cause sequelae in permanent successors? A systematic review. Dent Traumatol 31: 79-88. [Crossref]

57. Yousefi-Nooraie R, Dobbins M, Marin A, Hanneman R, Lohfeld L (2015) The evolution of social networks through the implementation of evidence-informed decision-making interventions: a longitudinal analysis of three public health units in Canada. Implement Sci 10: 166. [Crossref]

58. Schubotz RI, von Cramon DY (2001) Interval and ordinal properties of sequences are associated with distinct premotor areas. Cereb Cortex 11: 210-222. [Crossref]

Copyright: (C2017 Hupfeld KE. This is an open-access article distributed under the terms of the Creative Commons Attribution License, which permits unrestricted use, distribution, and reproduction in any medium, provided the original author and source are credited. 